\title{
Effect of Deposition Time on Structural and Electrical Properties of AZO thin films Deposited by Spray Pyrolysis
}

\author{
Sofea Nabila Hazmin, M. H. Mamat, and M. N. Amalina.
}

\begin{abstract}
Aluminium zinc oxide (AZO) thin films were deposited by spray pyrolysis method using different deposition time $10 \mathrm{~s}, 20$ $\mathrm{s}, 30 \mathrm{~s}, 40 \mathrm{~s}, 50 \mathrm{~s}$ and $60 \mathrm{~s}$. The structural and electrical properties of the AZO thin films were investigated by $X$-ray diffraction (XRD) and two-point probe system. XRD results reveal that all AZO thin films were polycrystalline with hexagonal wurtzite structure with a preferential oriental in the (101) plane. The crystalline size was calculated from Scherrer's formula were in the range from $31 \mathrm{~nm}$ to $44 \mathrm{~nm}$. According to the current-voltage (IV) measurement spectra, the AZO thin films deposited on Teflon substrates with different deposition time had a resistivity of $1.08 \mathrm{x}$ $10^{2} \Omega \mathrm{cm}$ to $9.78 \times 10^{1} \Omega \mathrm{cm}$ along with conductivity in the range of $1.02 \times 10^{-2} \mathrm{Scm}^{-1}$ to $9.26 \times 10^{-3} \mathrm{Scm}^{-1}$.
\end{abstract}

Index Terms-Aluminium zinc oxide (AZO), deposition time, electrical properties, structural properties, spray pyrolysis, thin film.

\section{INTRODUCTION}

$\mathrm{N}$ OWADAYS transparent conducting zinc oxide $(\mathrm{ZnO})$ have gained much interest on account of its appreciable optical and electrical properties [1], [2]. Besides, ZnO, an ntype semiconductor oxide component is non-toxic compared to other material such as indium tin oxide [3]. $\mathrm{ZnO}$ has a direct wide bandgap around $3.2 \mathrm{eV}$ to $3.37 \mathrm{eV}$, which makes $\mathrm{ZnO}$ optical wavelength spectrum transparent for a large wavelength of optical spectrum range [4]. Other advantages of the use of $\mathrm{ZnO}$ as transparent conductive contact are its abundance in nature, high chemical and mechanical stability, high exciton binding energy of $60 \mathrm{meV}$ and finally low cost [5], [6].

This paper is submitted on $28^{\text {th }}$ April 2020 and accepted on $10^{\text {th }}$ September 2020. Sofea Nabila Hazmin is currently taking her bachelor's degree of Electrical Engineering in Universiti Teknologi Mara (UiTM). M. H. Mamat and M. N. Amalina are with Nano Electronic Centre (NET) of UiTM.

Sofea Nabila Hazmin is with Faculty of Electrical Engineering, Universiti Teknologi Mara, Campus Shah Alam, 40450 Shah Alam, Selangor, Malaysia (e-mail: sofeahazmin@gmail.com).

M. N. Amalina, is with UiTM. She is now with the Faculty of Electrical Engineering, Johor branch, Campus Pasir Gudang, 81750 Masai, Johor, Malaysia. (e-mail: amalina0942@uitm.edu.my).

M. H. Mamat is with the Faculty of Electrical Engineering, Universiti Teknologi Mara, Campus Shah Alam, 40450 Shah Alam, Selangor, Malaysia (e-mail: mhmamat@salam.uitm.edu.my).

1985-5389/C 2021 The Authors. Published by UiTM Press. This is an open access article under the CC BY-NC-ND license (http://creativecommons.org/ licenses/by-nc-nd/4.0/).
Due to such remarkable properties of zinc oxide, zinc oxide became the most favourable semiconducting material for the application in solar cells [7], gas sensor [8], [9], humidity sensor [10], chemical sensor [11], photonic crystal, light-emitting diodes and ultra-violet (UV) detector [12], [13].

A variety of deposition techniques have been used to deposit aluminium zinc oxide (AZO) thin film for instance magnetron sputtering [14]-[16], pulse laser deposition [17], sol-gel [18], [19], hydrothermal, spin coating, chemical vapour deposition (CVD) and spray pyrolysis [21], [22]. All these deposition techniques should fulfil the requirement to produce a good quality AZO thin film. Among the listed techniques, spray pyrolysis is one of widely used technique for the preparation of AZO thin film due to its simplicity, affordable and non-vacuum method. In addition, spray pyrolysis is very useful for large scale production [19]. The different deposition parameters of spray pyrolysis such as spray time, nozzle to substrate distance, gas carrier pressure, type of gas carrier used, the concentration of precursor and substrate temperature play an important role in the determination of the quality of thin film deposited by spray pyrolysis. It has been proven that these deposition parameters give a significant effect on the properties of AZO thin film.

In the present work, we studied the effect of spray time on structural and electrical properties of sprayed AZO thin films. AZO thin films were deposited by spray pyrolysis method on Teflon substrates. This study can provide a better understanding and improvement of the quality of AZO thin films-based devices.

\section{EXPERIMENTAL DETAILS}

There are three stages of AZO thin film fabrication process, which are the beginning, middle and end process. In the beginning process, Teflon substrates and AZO solution were prepared. While the deposition of AZO thin films and the deposition of metal contact took placed in the middle process. The end process was the measuring process of AZO thin films for structural and electrical properties.

In the beginning process, Teflon substrate was prepared. First, Teflon substrates were cut into $2 \mathrm{~cm} \times 2 \mathrm{~cm}$ in size. Then, the substrates were cleaned with acetone, deionized (DI) water and methanol. The sequence as followed, acetone: DI water: 
methanol: DI water. The Teflon substrates were sonicated by Power-Sonic 405 for 20 minutes each. The substrates were cleaned to remove any contaminants on the surface of the substrates. Finally, the cleaned Teflon substrates were blown by nitrogen gas with position tilted 35 degrees. In this study, AZO solution was synthesized using four materials, Zinc Acetate Dehydrate (ZAD) $\left[\mathrm{Zn} \quad\left(\mathrm{CH}_{3} \mathrm{OO}\right) \cdot 2 \mathrm{H}_{2} \mathrm{O}\right]$ as precursor, Monoethanolamine (MEA) $\left(\mathrm{HOCH}_{2} \mathrm{CH}_{2}\right) \mathrm{NH}_{2}$ as a stabilizer, Aluminium Nitrate Nanahydrate $\mathrm{AL}\left(\mathrm{NO}_{3}\right)_{3} .9 \mathrm{H}_{2} \mathrm{O}$ as dopant, and 2-methoxyethanol as the solvent. The solutions were magnetically mixed and stirred for 3 hours with $80^{\circ} \mathrm{C}$ heat. The solution was then left overnight for ageing.

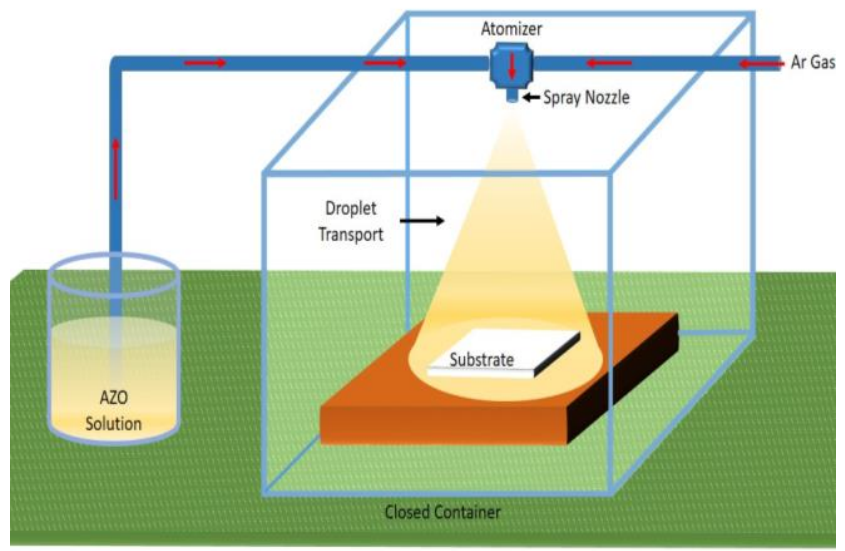

Fig. 1. Spray pyrolysis set-up.

In this deposition technique, the AZO solution was sprayed by means of a $0.2 \mathrm{~mm}$ nozzle assisted by argon gas which was kept with 1.0 bar carrier gas pressure over a hot substrate. The substrate was heated at $180^{\circ} \mathrm{C}$. AZO thin films were deposited onto cleaned Teflon substrate using spray pyrolysis technique at various deposition time. The spray pyrolysis technique setup was shown in Figure 1. The depositions time were 10, 20, $30,40,50$ and 60 seconds. The nozzle to substrate distance was held constant at $40 \mathrm{~cm}$. Finally, the deposited AZO thin films were dried in the furnace for 30 minutes with temperature $180^{\circ}$ C. Metal contact silver (Ag) deposition were done by the thermal evaporator.

The structural properties were studied by X-ray diffraction (XRD) measurements using Rigaku (D/MAX-2000) with $\mathrm{Cu}$ $\mathrm{K} \alpha$ radiation $(\lambda=0.154 \mathrm{~nm})$ at room temperature. The electrical properties were measured by the two-point probe system.

\section{RESULTS AND DISCUSSION}

\section{A. Structural Characterizations}

The X-Ray diffraction (XRD) spectra for Aluminium Zinc Oxide (AZO) thin films deposited at different deposition time were shown in Figure 2. All diffraction spectrum reveals all deposited films having preferential growth along (100) and (101) planes. Also, all thin films exhibit polycrystalline nature that belongs to JCPDS card No.36-1451, which was the hexagonal wurtzite type [22].

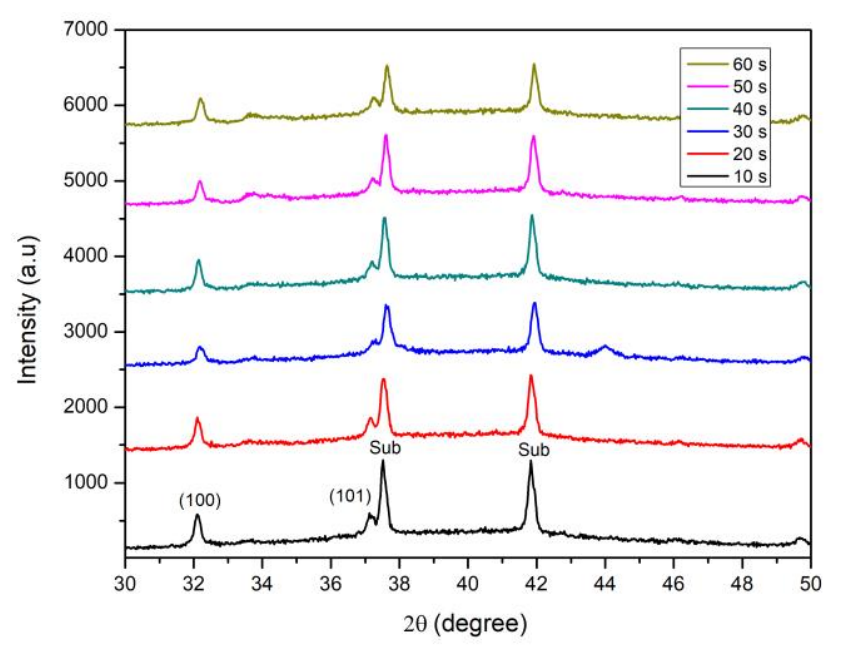

Fig. 2. X-Ray Diffraction spectra of AZO thin films deposited at different deposition time.

As deposited AZO samples show weak XRD intensity and broad peaks which indicated the amorphous structure and poor crystallinity of AZO thin films. The increments of deposition time do not significantly increase the crystal quality of the thin films as the sharp peaks were observed at samples with deposition time of $10 \mathrm{~s}, 20 \mathrm{~s}, 30 \mathrm{~s}$ and $40 \mathrm{~s}$ then the peaks become broad or dull from $40 \mathrm{~s}$ to $50 \mathrm{~s}$ onwards. These statements were proven by the full width at half maximum (FWHM) value of each sample at (101) plane. The FWHM values reflex the same trend as XRD spectrum where FWHM values of as deposited AZO thin films at $10 \mathrm{~s}, 20 \mathrm{~s}, 30 \mathrm{~s}, 40 \mathrm{~s}$, $50 \mathrm{~s}$ and $60 \mathrm{~s}$ to be $0.211^{\circ}, 0.209^{\circ}, 0.191^{\circ}, 0.168^{\circ}, 0.241^{\circ}$ and $0.230^{\circ}$ respectively.

The grain size of AZO thin films could be estimated using Scherrer's formula, as shown by the following equation (1):

$$
D=\frac{0.9 \lambda}{\beta \cos \theta}
$$

Where $D$ is grain size, $\lambda$ is x-ray wavelength of $1.54 \AA$. B is full width at half maximum (FWHM) in radian and $\theta$ is the diffraction angle. The calculated sizes from Scherrer's formula to be $35.69 \mathrm{~nm}, 35.90 \mathrm{~nm}, 39.30 \mathrm{~nm}, 44.70 \mathrm{~nm}, 31.16 \mathrm{~nm}$ and $32.59 \mathrm{~nm}$ as deposited samples and deposition time at $10 \mathrm{~s}, 20$ s, 30 s, 40 s, 50 s and 60 s respectively as shown in Figure 3. 


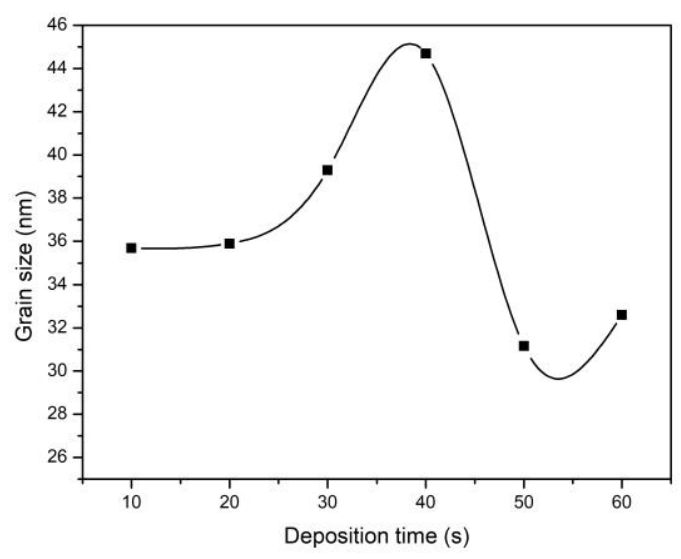

Fig. 3. Variation of grain size of AZO thin films at different deposition time.

\section{B. Electrical Characterization}

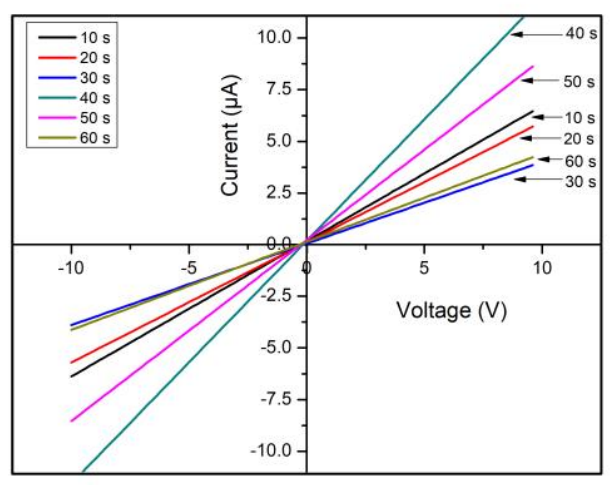

Fig. 4. I-V curve of AZO thin films at different deposition time.

Figure 4 shows the current-voltage (I-V) measurement spectra for AZO thin films at different deposition time using silver $(\mathrm{Ag})$ as metal contacts. It was found that the current intensity of the AZO thin films at respective voltage was highest at $40 \mathrm{~s}$ deposition time and lowest at AZO thin film deposited at $30 \mathrm{~s}$.

Figure 5 shows the electrical resistivity of AZO thin films at different spray time of $10 \mathrm{~s}, 20 \mathrm{~s}, 30 \mathrm{~s}, 40 \mathrm{~s}, 50 \mathrm{~s}$ and $60 \mathrm{~s}$. The resistivity was calculated by the following equation (2):

$$
\rho=\left(\frac{V}{l}\right) \frac{w t}{l}
$$

where $V$ is the voltage applied, $I$ is the measured current, $w$ is the width of the electrode, $t$ is the thickness of the film, and $l$ is the length between two electrodes.

Based on figure 5, the lowest resistivity was $3.26 \times 10^{1} \Omega \mathrm{cm}$, which have a thickness of $1.3 \mu \mathrm{m}$ and $40 \mathrm{~s}$ spray time which also the highest value of thickness between other samples. Thus, when spray time increases, the crystallite size of the sample also increases. It can be explained by the grain boundary defects due to the state of oxygen acceptor [23]. It seems that grain boundary scattering of charge was reduced, resulting in the reduction in resistivity.

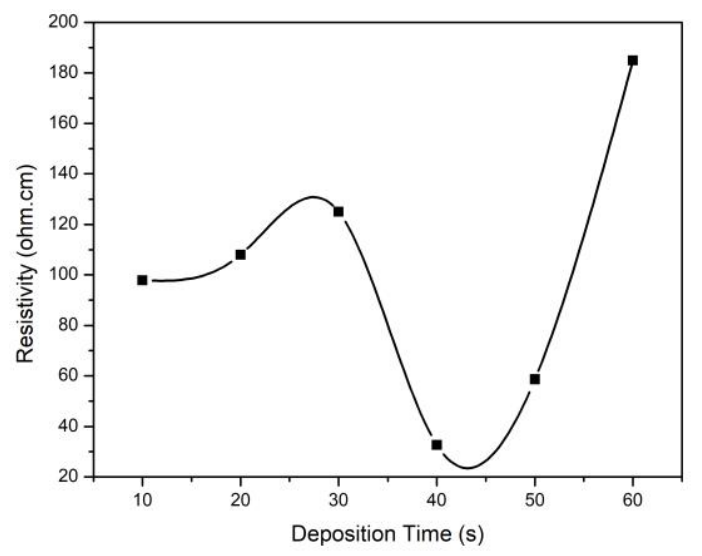

Fig. 5. Variation of resistivity with different deposition time.

Conductivity is inversely perpendicular to the resistivity of the thin film, which gives the formula of conductivity in equation (3):

$$
\sigma=\frac{1}{\rho}
$$

where $\sigma$ is the conductivity and $\rho$ is the resistivity of a thin film. Figure 6 shows the electrical conductivity of AZO thin films at different spray time calculated from I-V curve data. It was observed that the conductivity of AZO thin film highest at sample deposited at deposition time $40 \mathrm{~s}$. The conductivity of AZO decreases as the deposition time decreases but increases after $30 \mathrm{~s}$. However, after the increment of the sample deposited at $40 \mathrm{~s}$, the conductivity continues to decline.

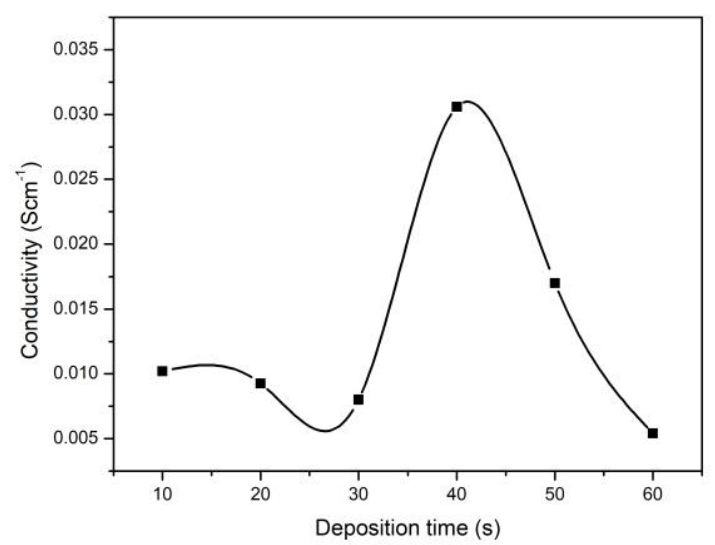

Fig. 6. Electrical conductivity of AZO thin films at different deposition time.

This trend was similar to the grain size trend with different spray time of AZO thin films. There were many reasons corresponds to conductivity that relates to crystallite size which was the structural modification that occurs perpendicularly to the substrate surface and the changing stacking mode where it affects the dislocation and distortion of the orientation resulting in the mobility of charge carrier which will correspond to 
increase in resistivity where it also leads to decrease in conductivity [24].

\section{CONCLUSION}

In conclusion, the properties of AZO thin films deposited on a Teflon substrate prepared at different deposition time have been investigated. Through the study of the effect of deposition time on structural and electrical properties of AZO thin films deposited by spray pyrolysis, AZO thin film prepared at $40 \mathrm{~s}$ spray time was found to exhibit quality thin film with preferential growth compared to other AZO thin films. The increment of crystallite size could improve the electrical properties in the thin film. The conductivity of AZO thin films was found to be highest at $40 \mathrm{~s}$ which was $3.06 \times 10^{-2} \mathrm{Scm}^{-1}$ with lowest resistivity value of $3.26 \times 10^{1} \Omega \mathrm{cm}$ also, have the highest crystallite size value of $44.7 \mathrm{~nm}$.

\section{ACKNOWLEDGEMENT}

This work was supported in part by the Ministry of High Education under Grant (600-IRMI/FRGS 5/3 (085/2017)). The author would like to acknowledge all members of Nano Electronic Centre (NET), NANO-SciTech Centre (NST), Faculty of Electrical Engineering and Universiti Teknologi Mara (UiTM) for providing the facilities.

\section{REFERENCES}

S. Zargou, S. M. Chabane Sari, A. R. Senoudi, M. Aida, N. Attaf, and I. F. Hakem, "Effect of solution flow rate on growth and characterization of nanostructured $\mathrm{ZnO}$ thin films deposited using spray pyrolysis," J. Mater. Environ. Sci., vol. 7, no. 9, pp. 3134-3147, 2016.

[2] Y. Vijayakumar, P. Nagaraju, V. Yaragani, S. R. Parne, N. S. Awwad, and M. V. Ramana Reddy, "Nanostructured Al and Fe codoped $\mathrm{ZnO}$ thin films for enhanced ammonia detection," Phys. B Condens. Matter, vol. 581, p. 411976, Mar. 2020.

[3] S. Hossain, G. D. A. Quaderi, K. M. A. Hussain, and T. Faruqe, "Synthesis and Characterization of Undoped and Aluminum Doped Zinc Oxide Thin Films using Thermal Evaporation Method," vol. 27, no. 1, pp. 25-31, 2018.

[4] B. V. Shrisha, S. Bhat, D. Kushavah, and K. Gopalakrishna Naik, "Hydrothermal growth and characterization of Al-doped $\mathrm{ZnO}$ nanorods," in Materials Today: Proceedings, 2016, vol. 3, no. 6, pp. 1693-1701.

[5] A. Báez-Rodríguez et al., "ZnO nanocolumns synthesized by chemical bath process and spray pyrolysis: Ultrasonic and mechanical dispersion of $\mathrm{ZnO}$ seeds and their effect on optical and morphological properties," J. Lumin., vol. 218, p. 116830, Feb. 2020.

[6] H. Ali et al., "Influence of nickel doping on the energy band gap, luminescence, and magnetic order of spray deposited nanostructured ZnO thin films," J. Alloys Compd., vol. 816, p. 152538, Mar. 2020.

[7] J. Ma et al., "Low temperature $\mathrm{ZnO} / \mathrm{TiOx}$ electron-transport layer processed from aqueous solution for highly efficient and stable planar perovskite solar cells," Mater. Today Energy, vol. 14, p. 100351, Dec. 2019.

[8] Q. Zhou, W. Zeng, W. Chen, L. Xu, R. Kumar, and A. Umar, "High sensitive and low-concentration sulfur dioxide ( $\mathrm{SO} 2)$ gas sensor application of heterostructure $\mathrm{NiO}-\mathrm{ZnO}$ nanodisks," Sensors Actuators, B Chem., vol. 298, p. 126870, Nov. 2019.

[9] J. Chao, Y. Chen, S. Xing, D. Zhang, and W. Shen, "Facile fabrication of $\mathrm{ZnO} / \mathrm{C}$ nanoporous fibers and $\mathrm{ZnO}$ hollow spheres for high performance gas sensor," Sensors Actuators, B Chem., vol. 298, p. 126927, Nov. 2019.

[10] A. S. Ismail et al., "Intrinsic $\mathrm{ZnO} / \mathrm{Al}$-doped $\mathrm{ZnO}$ Homojunction: Structural and Optical Properties," Indones. J. Electr. Eng. Comput.
Sci., vol. 12, no. 1, p. 393, Oct. 2018.

[11] R. Wahab, N. Ahmad, M. Alam, and J. Ahmad, "Nanorods of ZnO: An effective hydrazine sensor and their chemical properties," Vacuum, vol. 165, pp. 290-296, Jul. 2019.

[12] A. A. Abuelsamen, S. Mahmud, A. Seeni, N. H. M. Kaus, and O. F. Farhat, "Effects of precursor concentrations on the optical and morphological properties of $\mathrm{ZnO}$ nanorods on glass substrate for $\mathrm{UV}$ photodetector," Superlattices Microstruct., vol. 111, pp. 536-545, Nov. 2017.

[13] O. F. Farhat et al., "A study of the effects of aligned vertically growth time on $\mathrm{ZnO}$ nanorods deposited for the first time on Teflon substrate," Appl. Surf. Sci., vol. 426, pp. 906-912, Dec. 2017.

[14] R. S. Tondare, B. W. Shivaraj, H. N. Narasimhamurthy, M. Krishna, and T. K. Subramanyam, "Effect of deposition time on structural, electrical and optical properties of Aluminium doped $\mathrm{ZnO}$ thin films by RF magnetron sputtering," Mater. Today Proc., vol. 5, no. 1, pp. 2710-2715, Jan. 2018.

[15] D. K. Kim and H. B. Kim, "Room temperature deposition of Aldoped $\mathrm{ZnO}$ thin films on glass by $\mathrm{RF}$ magnetron sputtering under different Ar gas pressure," J. Alloys Compd., vol. 509, no. 2, pp. 421425, 2011.

[16] N. Ameera et al., "Nanocolumnar zinc oxide as a transparent conductive oxide film for a blue InGaN-based light emitting diode," Ceram. Int., vol. 41, no. 1, pp. 913-920, Jan. 2015.

[17] K. Singkaselit, A. Sakulkalavek, and R. Sakdanuphab, "Effects of annealing temperature on the structural, mechanical and electrical properties of flexible bismuth telluride thin films prepared by highpressure RF magnetron sputtering," Adv. Nat. Sci. Nanosci. Nanotechnol., vol. 8, no. 3, p. 035002, Jul. 2017.

[18] S. H. Sabeeh and R. H. Jassam, "The effect of annealing temperature and $\mathrm{Al}$ dopant on characterization of $\mathrm{ZnO}$ thin films prepared by solgel method," Results Phys., vol. 10, pp. 212-216, Sep. 2018.

[19] K. N. Tonny, R. Rafique, A. Sharmin, M. S. Bashar, and Z. H. Mahmood, "Electrical, optical and structural properties of transparent conducting $\mathrm{Al}$ doped $\mathrm{ZnO}$ (AZO) deposited by sol-gel spin coating," AIP Adv., vol. 8, no. 6, p. 065307, Jun. 2018.

[20] A. Hafdallah, "Effect of the Nozzle-Substrate Distance on the Structural and Optical Properties of $\mathrm{ZnO}$ Thin Films Deposited by Spray Pyrolysis Technique," Am. J. Nano Res. Appl., vol. 5, no. 6, p. 87, 2017.

[21] M. Nasiri and S. M. Rozati, "Muscovite mica as a flexible substrate for transparent conductive AZO thin films deposited by spray pyrolysis," Mater. Sci. Semicond. Process., vol. 81, pp. 38-43, Jul. 2018.

[22] O. F. Farhat, M. M. Halim, M. J. Abdullah, M. K. M. Ali, N. M. Ahmed, and M. Bououdina, "Fabrication and characterization of $\mathrm{ZnO}$ nanowires by wet oxidation of $\mathrm{Zn}$ thin film deposited on Teflon substrate," Superlattices Microstruct., vol. 86, pp. 236-242, Oct. 2015.

[23] Z. Ben Achour, T. Ktari, B. Ouertani, O. Touayar, B. Bessais, and J. Ben Brahim, "Effect of doping level and spray time on zinc oxide thin films produced by spray pyrolysis for transparent electrodes applications," Sensors Actuators A Phys., vol. 134, no. 2, pp. 447451, Mar. 2007.

[24] F. Khediri, A. Hafdallah, and M. Bouhelal, "Effect of Deposition Time on Structural and Optical Properties of $\mathrm{ZnO}$ Thin Films Deposited by Spray Pyrolysis," Defect Diffus. Forum, vol. 397, pp. 81-87, Sep. 2019.

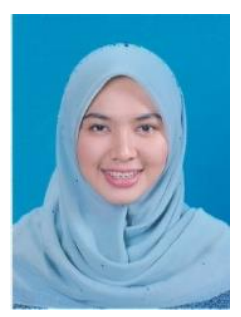

Sofea Nabila Hazmin was born in Terengganu, Malaysia on May 19, 1994. She received a diploma in Science in 2015 and Bachelor of Industrial Physics (Hons) in 2018 from Universiti Teknologi MARA (UiTM), Malaysia. She is currently taking a Master of Electrical Engineering in UiTM major in nanotechnology and UltraViolet (UV) detector. She is a member of UiTM Postgraduate Society. 


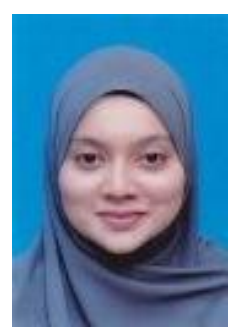

Dr Nur Amalina Binti Muhamad is one of the members in the Board of Engineers Malaysia (BEM) and currently she is a senior lecturer at Universiti Teknologi MARA (UiTM). She graduated Bachelor and $\mathrm{PhD}$ in Electrical Engineering from UiTM. She also the head of Unit 'Pengajaran, Pembelajaran dan Latihan Staff', the academic advisor of UiTM Pasir

Gudang Campus, a committee of Malaysian Qualifications Agency (MQA) and a committee of Academic Timetable of UiTM Campus.

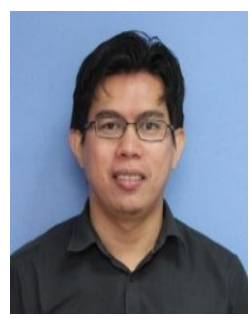

PM. Ir. Ts. Dr Mohamad Hafiz Bin Mamat obtained his Bachelor of Electrical \& Electronic Engineering and Information Engineering from Nagoya University. Then, he further his studies at Universiti Teknologi MARA (UiTM), Malaysia taking MSc and $\mathrm{PhD}$ in Nanoelectronic. $\mathrm{He}$ is currently the head of NANO-ElecTronic Centre (NET) at Faculty of Electrical Engineering UiTM Shah Alam. 